\title{
Total Artificial Heart as the Destination Therapy: A Review
}

\author{
Abdul Mannan Khan Minhas ${ }^{1}$, Salman Assad ${ }^{2}$, Maryam Khan ${ }^{3}$, Saba Ahmed ${ }^{3}$, Muhammad \\ Shahzeb Khan ${ }^{4}$, Sriharsha Chakravarthi Athota ${ }^{1}$, Jonathan Constantin ${ }^{5}$
}

${ }^{1}$ Internal Medicine, Orange Park Medical Center, Fl, USA

${ }^{2}$ Shifa College of Medicine, Islamabad, Pakistan

${ }^{3}$ Medical Student, Dow Medical College, Karachi, Pakistan

${ }^{4}$ Internal Medicine, John H. Stroger Jr. Hospital of Cook County, Chicago, USA

${ }^{5}$ Cardiology, First Coast cardiovascular, Fl, USA

Received: 20 May, 2017 ; Accepted: 06 June, 2017; Published: 16 June, 2017

*Corresponding author: Abdul Mannan Khan Minhas, MD, Internal Medicine, Orange Park Medical Center, Fl, USA, Tel no: +1(904)770-0101, Fax no: +1(904) 639-201; E-mail: Abdul.Minhas@hcahealthcare.com

\begin{abstract}
Introduction: For the patients awaiting cardiac transplantation, mechanical circulatory support has been widely utilized in the form of left ventricular assist device or total artificial heart. Both total artificial heart and left ventricular assist device have been approved for the use as a bridge to transplantation therapy; however only left ventricular assist device has been approved for use as the destination therapy. The purpose of this review is to establish, using this literature, the possibility for the artificial heart transplant to be used as destination therapy besides highlighting the recent developments in this area of research in order to narrate the future of artificial heart transplantation.
\end{abstract}

Review: 5 studies including 3 case reports, one retrospective multicenter study and one clinical trial were identified following a rigorous literature search. Four studies reported the outcomes related to SynCardia total artificial heart implantation whereas one study presented the results of the clinical trial conducted for the AbioCor total artificial heart. Although total artificial heart has established the reputation of a successful device for bridge to transplantation therapy, attempts have been made for the implantation of total artificial heart as destination therapy to provide a replacement of failing human heart.

Conclusion: A limited pool of studies is available regarding the usage of total artificial heart as the destination therapy that has shown promising results, but numerous issues like biocompatibility, durability, reliability of power supply, dependency on external console for power, and control of complications including thromboembolism, hemorrhage and infections remain imminent challenges for the scientists that need to be addressed before total artificial heart can completely overtake the role of natural human heart.

Keywords: Total Artificial Heart; Destination therapy

\section{Introduction}

Heart failure has a fair share of disease burden worldwide, approximately affecting more than 30 million individuals globally [1]. Advanced heart failure has a very poor prognosis despite being on optimized medical therapy due to which it has become one of the major health concerns. Unfortunately, there is a huge mismatch in demand and supply of heart donors and recipients. For the patients awaiting cardiac transplantation, mechanical circulatory support has been widely utilized in the form of left ventricular assist device (LVAD) or total artificial heart (TAH). Both TAH and LVAD have been approved for the use as a bridge to transplantation therapy (BTT); however, only LVAD has been approved for use as the destination therapy (DT) [2].

Until now, almost 1600 TAHs have been transplanted. According to a trial conducted between 1993 and 2002 for Cardio West TAH on 81 patients, the rate of survival to transplantation was 79 percent and one-year and five-year survival rates after transplantation were 86 and 64 percent respectively [3]. Following the success of this trial, Food \& Drug Administration (FDA) granted approval to Cardio West TAH (now being marketed as SynCardia TAH), which is currently the only FDA and Health Canada approved artificial heart commercially available in the market that is being used in over 50 centers of the world mainly as a BTT. Since its advent, SynCardia has been through numerous biomechanical modifications resulting in reduction of the associated complications and discomfort that existed at a higher percentage a decade ago. Smaller SynCardia has also been designed for the use in patients with smaller body habitus and pediatric population whereas the use of portable freedom driver allows the mobility of the patients and safe discharge from the hospital [4].

The scarcity of organ donors and mortality associated with post-transplant graft rejection highlights the need for DT. 
Although LVAD technology has established itself as a successful DT but in a subset of patients who have concurrent right heart failure or other cardiac structural abnormalities where LVAD is contraindicated, use of TAH is more appropriate. Moreover, a higher complication profile associated with LVAD such as right ventricular failure, valvular damage and arrhythmias points towards the dominance of TAH over LVAD [5]. Nevertheless, TAH has not been recommended for DT as more clinical trials are needed to evaluate the efficacy of artificial hearts for its application in DT. FDA has recently approved a clinical study of 19 patients for the effectiveness of SynCardia as the destination therapy [6]. A limited literature exists in the form of clinical studies and case reports highlighting the implications of utilizing artificial heart for long-term therapy or as destination therapy. The purpose of this review is to establish, using this literature, the possibility for the artificial heart transplant to be used as DT besides highlighting the recent developments in this area of research in order to narrate the future of artificial heart transplantation.

\section{Methods}

Data was extracted after a thorough literature search conducted in May 2017 utilizing search engines PubMed, Embase, Medline by using the keywords artificial heart transplant AND total artificial heart AND SynCardia or Cardio West or artificial heart transplant as long-term therapy or artificial heart transplant as destination therapy. Only articles written in English were considered. An extensive search for bibliographies on the topic of cardiac transplantation yielded no relevant article. Experts in the field were contacted to identify anything missed by the search.

Since the focus of this review was destination therapy, studies meeting the following criteria were included in the analysis: Case reports or clinical studies reporting the application of artificial heart as destination therapy; studies evaluating the outcome after implanting TAH as BTT for the long term before transplantation, and studies conducted on human subjects. Only articles written in English were considered. There was no restriction on the sample size, year of study and type of study. Since no clinical trial has been conducted in this regard, so all the clinical trials and prospective or retrospective studies that only reported success and complications related to TAH used as bridge to transplant for a short period of time were excluded as these studies didn't meet the inclusion criteria. Firstly, the titles and abstracts of all the retrieved articles were reviewed. Full texts of articles that met the eligibility criteria were extracted. These articles were then separately reviewed by another author.

Patient demographics, Interagency Registry for Mechanical Assisted Circulatory Support (INTERMACS) scale profile, New York Heart Association (NYHA) class and preexisting cardiac pathology were considered. The main outcomes of interest were median support time, improvement of symptoms after an intervention, post intervention mortality, complications after intervention and post-transplantation mortality. The details of the methodology involved in each trial were given priority for efficient comparison of the studies and interpretation of results.

\section{Results}

The search generated only five relevant studies; 3 case reports, one retrospective multicentre study and one clinical trial. Four studies reported the outcomes related to SynCardia TAH implantation whereas one study presented the results of the clinical trial conducted for AbioCor TAH [7]. All the studies were reported from Europe except one [7]. The participants were predominantly old, averaging around 50 years of age and all studies included participants who had a biventricular failure. All patients later underwent donor cardiac transplantation after long term support on TAH except in two studies $[7,8]$. The baseline characteristics of the studies are mentioned in Table 1.

\begin{tabular}{|c|c|c|c|c|c|c|c|}
\hline Serial number & $\begin{array}{l}\text { First author and } \\
\text { duration of study }\end{array}$ & Type of study & $\begin{array}{l}\text { Location of } \\
\text { centre }\end{array}$ & Age & Cardiac pathology & INTERMACS class & $\begin{array}{l}\text { Duration of support on } \\
\text { TAH }\end{array}$ \\
\hline 1 & Gerosa G, 2015 & Case Report & Italy & 55 & $\begin{array}{l}\text { Cardiogenic shock and } \\
\text { multiple organ failure }\end{array}$ & INTERMACS 1 & 1374 days \\
\hline 2 & $\begin{array}{l}\text { Spiliopoulos S, } \\
2014\end{array}$ & Case Report & Germany & 74 & $\begin{array}{c}\text { Infiltrative } \\
\text { Cardiomyopathy, } \\
\text { Biventricular failure }\end{array}$ & INTERMACS 2 & 325 days and onwards \\
\hline 3 & $\begin{array}{c}\text { Torregrossa G, } \\
1989-2011\end{array}$ & $\begin{array}{l}\text { Retrospective } \\
\text { Study }\end{array}$ & $\begin{array}{l}\text { Multicentre } \\
\text { Study }\end{array}$ & $50 \pm 1.57$ & $\begin{array}{c}\text { Dilated Cardiomyopathy } \\
\text { in } 32 \text { patients } \\
\text { Ischemic } \\
\text { Cardiomyopathy in } 18 \\
\text { patients } \\
\text { Other causes in } 9 \\
\text { patients }\end{array}$ & $\begin{array}{l}\text { INTERMACS } 1 \text { in } \\
23 \text { patients } \\
\text { INTERMACS } 2 \text { in } 7 \\
\text { patients } \\
\text { INTERMACS } 3 \text { in } 3 \\
\text { patients }\end{array}$ & $\begin{array}{l}\text { Median } 554 \text { days } \\
\text { Range=365-1374 }\end{array}$ \\
\hline 4 & $\begin{array}{l}\text { Loforte A, } \\
2011\end{array}$ & Case Report & Italy & 38 & $\begin{array}{l}\text { Dilated cardiomyopathy, } \\
\text { biventricular failure }\end{array}$ & INTERMACS 2 & 832 days \\
\hline 5 & 2001-2004 & Clinical trial & US & $50 \pm 1.57$ & Biventricular failure & & 512 days \\
\hline
\end{tabular}




\section{Study 1}

The University of Padova, Italy, in this case, reported the longest bridge to transplant worldwide using a 70cc TAH in a 55 years old man. CardioWest TAH (CW-TAH) was implanted after a patient developed cardiogenic shock and multi organ failure due to sepsis (INTERMACS level 1) following intra-aortic balloon pump (IABP) insertion. He was supported on Berlin Heart Excor drive unit for 1191 days and experienced $24 \%$ increase in peak oxygen consumption besides improvement in the quality of life. However, when the external BH Excor console was exchanged with the Freedom Driver, a reduction of peak oxygen consumption was observed with a significant reduction in quality of life. He was successfully transplanted after a total of 1374 days of support, with 1170 days out of the hospital. The explanted CW-TAH was analyzed and no thrombus formation was detected inside the ventricular chambers, nor pannus on the mechanical valve. Warfarin, aspirin, dipyridamole and pentoxifylline were given as anticoagulants [9].

\section{Study 2}

This study from Germany described the first case of SynCardia TAH implanted as destination therapy in a 74-year-old male patient with infiltrative cardiomyopathy secondary to amyloidosis. The patient had a serious biventricular failure (NYHA 4 and INTERMACS 2) and after an unsuccessful attempt with LVAD, he was switched to SynCardia TAH. The only complication developed was anemia with low degree haemolysis. The patient was discharged after 113 days and supported for 325 days onwards [8].

\section{Study 3}

This retrospective multicentre study reviewed the outcomes in all patients supported with SynCardia TAH for more than 1 year. Clinical data was retrieved from SynCardia Systems Inc. of patients supported on TAH from 1989 to 2011. Out of 1075 patients, 47 patients were included based on inclusion criteria. The mean age of patients was $50 \pm 1.57$ years, median support time was 554 days and median body surface area (BSA) was 2.02 square meters (Table 2).

Twelve patients died while on device support. However, three-fourths of the patients were successfully transplanted after one year of support on TAH and 1 patient was supported onwards. Only five cases of device failure were reported out of which two patients died due to membrane rupture. Major complications that developed during this period were systemic infections (53\%), thromboembolic events (TE) (19\%), driveline infections (27\%), and hemorrhagic events (HE) (14\%) (Table 3).

There was a statistically significant effect of BSA on outcomes. Patients with BSA less than 1.8 square meters were found to have increased incidence of death ( $p=0.0045)$, hemorrhagic events $(p=0.009)$, and systemic infections $(p=0.008)$. A comparison of the rate of TE events with previous studies showed that long-term support on TAH does not increase the risk of TE events and fewer deaths resulted from TE events as compared to hemorrhagic episodes [10].

\begin{tabular}{|c|c|}
\hline & All Patients $(\mathrm{N}=47)$ \\
\hline \multicolumn{2}{|l|}{ Age at implant (years) } \\
\hline Median & 49 \\
\hline Range & $19-69$ \\
\hline \multicolumn{2}{|l|}{ Gender } \\
\hline Male & $41(87 \%)$ \\
\hline \multicolumn{2}{|l|}{ Height (centimeters) } \\
\hline Median & 180 \\
\hline Range & $155-202$ \\
\hline \multicolumn{2}{|c|}{ Body Surface Area (square meters) } \\
\hline Median & 2.02 \\
\hline Range & $1.64-2.4$ \\
\hline \multicolumn{2}{|l|}{ INTERMACS Status } \\
\hline Class 2 & 7 \\
\hline Class 3 & 3 \\
\hline NA & 14 \\
\hline \multicolumn{2}{|l|}{ Cause of Heart Failure } \\
\hline Dilated cardiomyopathy & $33(49 \%)$ \\
\hline Ischemic cardiomyopathy & $18(32 \%)$ \\
\hline Others & $9(19 \%)$ \\
\hline \multicolumn{2}{|l|}{ Previous Intervention } \\
\hline Previous LVAD/IABP & $22(46.8 \%)$ \\
\hline Previous IPPV & 23 (49\%) \\
\hline Previous Cardiac Surgery & $19(40 \%)$ \\
\hline Previous RRT & $18(38 \%)$ \\
\hline
\end{tabular}

NA, not available; LVAD, left ventricular assist device; IABP, intra-aortic balloon pump; IPPV, intermittent positive pressure ventilation; RRT, renal replacement therapy; INTERMACS: Interagency Registry for Mechanical Assisted Circulatory Support 
Table no. 3: Adverse Events and Outcomes reported in study 3.

\begin{tabular}{|l|c|}
\multicolumn{1}{c|}{ Adverse Events and Outcomes } & Number of Patients \\
\hline Hemorrhagic events & 7 \\
Transplanted Alive & 5 \\
Died & 2 \\
\hline Thromboembolic Events & 9 \\
Transplanted Alive & 7 \\
Died & 2 \\
\hline Device Failure & 5 \\
Transplanted Alive & 3 \\
Dead & 2 \\
\hline
\end{tabular}

\section{Study 4}

AbioCor TAH developed by Abiomed Inc. is the artificial heart designed primarily to serve as destination therapy. After FDA granted approval in 20017, 14 patients with 30-day mortality risk greater than $70 \%$ were implanted with Abiocor between 2001 and 2004. This study reports the outcome of AbioCor implantation.

Two patients died at surgery due to bleeding. The 12 surviving patients lived up to 512 days on Abiocor support but developed multiple complications eventually leading to death. Major adverse events reported were bleeding and infections followed by cerebrovascular accidents (CVA). The major cause of death was CVA. Half of the CVA-related deaths were due to factors preventing adequate anticoagulation of the subjects while the remaining half were due to inflow structure thrombosis. Device thrombosis was observed upon autopsy. Device malfunction consumed the life of two patients; one was due to the membrane wearing out at 17 months, while the second was due to motor bearing failure at 4.8 months. Moreover, one-third deaths were due to multiple organ failures because of following causes; a vein puncture from a dialysis catheter leading to abdominal bleeding and subsequent sepsis, an unhealed suture wound, and two cases of pre-existing hepatic dysfunction that failed to reverse [7].

\section{Discussion}

The journey of artificial heart started with Jarvik but it was not until 2004 that FDA, following the success of trial conducted by Copeland et al., granted approval for CardioWest, launching an era of artificial heart transplantation as the bridge to destination therapy $[3,7]$. SynCardia TAH is a pneumatically driven, pulsatile biventricular replacement system made of semirigid polyurethane, capable of flows of $>9$ liters/minute, indicated for use as a BTT in cardiac transplant candidates at risk of imminent death from non-reversible biventricular failure. Although LVAD has established itself as a successful BTT, but in cardiac pathologies where LVAD is contraindicated, including biventricular failure, intractable arrhythmias, irreparable ventricular anatomical defects, mechanical prosthetic valve replacement, and cardiac neoplasms, the dominance of TAH over LVAD is undisputable. Moreover, the design of TAH offers several advantages relative to present continuous flow LVADs, like reduced thrombosis and stroke rates, reduced after load and preload sensitivity, and a re- duction in device-induced bleeding [12].

In this review, we analyzed the existing literature to highlight the application of TAH as destination therapy. Since FDA has recently approved the trial for TAH implantation as destination therapy, convincing data is lacking in the form of clinical trials and RCT supporting the use of the TAH as destination therapy. However, numerous efforts have been made worldwide by physicians in attempting destination therapy or long-term therapy by SynCardia in individuals who had absolute contraindications for LVAD. More than 92 patients have been supported with a CardioWest TAH for more than one year.5 All studies were in harmony that long term support on SynCardia beyond one year was not associated with an increase in thromboembolic complications and the rate of thromboembolic complications was independent of the duration of support and anticoagulation profile. This finding was consistent with previous studies, suggesting that TAH can be implanted as destination therapy while following existing anticoagulation protocols.

The ventricles in SynCardia are attached to pneumatic drivelines, which are connected to back of the external console. The console includes a monitoring computer that provides noninvasive diagnostic information. It has been through numerous modifications to allow early discharge from the hospital and recently SynCardia introduced flexible portable freedom driver to enhance patient mobility with a TAH, as does the AbioCor, which is a fully implantable TAH. One case study reported deterioration of patient on shifting to Freedom portable driver but this finding could not be found in other studies. Therefore, a larger patient group presenting with different comorbidity and clinical characteristics is needed to assess the suitability of Freedom driver along with CW-TAH for destination therapy. However, the pneumatic drivelines passing through the skin to the exterior to deliver and withdraw driving compressed air to the implanted moving diaphragms were reported as a source of infection in one-third of the patients in the study by Torregrossa et al. A French study also reported the same findings in the patients supported for more than a year [12]. These data highlight the need for maintaining a high suspicion for infections in patients supported for the long term on a SynCardia TAH besides developing new systems to power implanted driving units which are fully operational without interruption of skin barriers in order to decrease the risk of infections. 
None of the studies in our review reported intraoperative mortality at the time of the cardiac transplantation when the device was removed from the chest. The successful surgical intervention and prompt management and prevention of postoperative complications were considered important factors in improving the outcome of heart transplantation in patients supported for the long term with a TAH. $72 \%$ of the patients with a SynCardia TAH underwent successful cardiac transplantation in the study by Torregrossa et al. This outcome was confirmed by other studies as well; the study by Copeland et al. reported $86 \%$ survival rates and a French study reported that the actual estimate of survival under TAH support was found constant between 120 and 360 days $[13,14]$. It can be secondary to long-term adequate systemic flow provided by TAH to fulfill all the metabolic and physiological demands, pointing towards its suitability as a completely implantable $\mathrm{TAH}$, although more trials are needed to support this notion.

Device failure was reported in three studies out of which one study reported device failure in AbioCor Hemorrhagic events were found highly associated with AbioCor implantation whereas only one study reported hemorrhage association with SynCardia $[7,8,10]$. However, as suggested by the literature, hemorrhage remains a major limitation a result of antithrombotic therapy started to prevent thrombotic complications secondary to bulky design. Nantes group, La Pitie group and Arizona group case series reported bleeding in $22 \%, 35 \%$ and $43 \%$ of the patients respectively [5]. Neurological complications as embolic strokes were reported by two studies $[7,10]$.

Following the success of SynCardia as BTT, the idea of developing a TAH for DT gained traction which led to the development of AbioCor, a prototype of artificial heart designed to be totally implanted in the body without any external console. This device consisted of two pumping compartments with flexible polyether-urethane-made membranes alternately compressed by an internal mechanism of alternating low-viscosity hydraulic fluid between the two sacs by a centrifugal pump (electrohydraulic unit), which was powered by an internal battery. Only one study conducted from 2001 to 2004 reported the outcomes of AbioCor TAH. All the patients died following complications like device failure, cerebrovascular accidents, bleeding, and sepsis leading to multiple organ failure, due to which AbioCor was not successful in gaining approval. However, in 2006, FDA analyzed the results and approved the humanitarian device exemption (HDE) for AbioCor in end-stage biventricular heart failure patients who were neither candidates for LVAD nor for heart transplantation [7].

The role of TAH as DT is still in initial stages and needs to be investigated further. Multiple technical challenges are still encountered with the development of a totally implantable $\mathrm{TAH}$ for use as destination therapy like proper fitting of device within the mediastinum of a majority of patients, generation of adequate cardiac output according to the physiological needs with a balance in systemic and pulmonary circulation, dependence upon an internal battery, and efficient function without generating heat and thrombi. Meanwhile, numerous research investigations are taking place to overcome the existing complica- tions. CARMAT (Carmat, France) is a recently developed electro hydraulic TAH, that consists of valves and ventricles made up of biocompatible materials that have shown promising results in reducing thrombosis-associated complications. It was successfully implanted in two patient, supporting one patient for 75 days and another one for more than 4 months after being discharged from the hospital $[5,15]$. Multiple studies are focusing on miniaturization of TAH in order to reduce complications and to implant in small body habitus. SynCardia has introduced a new 50cc-TAH, which received a Humanitarian Device Designation for the pediatric bridge to transplant and was successfully implanted in a pediatric patient with BSA less than 1.7 square meters [16]. Bivacor and One Heart are other miniature artificial hearts under development [5]. Moreover, Germany is developing a new TAH known as ReinHeart, which has better durability and biocompatibility as compared to AbioCor and SynCardia. Successful animal trials and in vitro results have been reported, pointing towards the possibility of replacing donor dependent heart transplantation in the near future [17].

\section{Conclusion}

The growing limitations on the number of donors besides the rising percentage of end-stage heart failure patients are posing a great challenge for physicians in the very near future. Although TAH has established the reputation of a successful device for BTT, attempts have been made for the implantation of TAH as destination therapy to provide a replacement of failing human heart. A limited pool of studies is available in this regard that has shown promising results, but numerous issues like biocompatibility, durability, reliability of power supply, dependency on external console for power, and control of complications including thromboembolism, hemorrhage, and infections remain imminent challenges for the scientists that need to be addressed before TAH can completely overtake the role of natural human heart. Our study aims to encourage fellow clinicians and researchers to further investigate into the prospects of TAH as DT that would eventually prompt the government agencies to promote research in this area.

\section{References}

1. Ziaeian B, Fonarow GC. Epidemiology and aetiology of heart failure. Nat Rev Cardiol. 2016;13(6):368-378. doi: 10.1038/nrcardio.2016.25

2. Cooley DA. The total artificial heart. Nat Med. 2003;9(1):108-111. doi: 10.1038/nm0103-108

3. Copeland JG, Smith RG, Arabia FA, Nolan PE, Sethi GK, Tsau PH, et al. Cardiac replacement with a total artificial heart as a bridge to transplantation. N Engl J Med. 2004;351(9):859-867. doi: 10.1056/NEJMoa040186

4. Demondion P, Fournel L, Niculescu M, Pavie A, Leprince P. The challenge of home discharge with a total artificial heart: the La Pitie Salpetriere experience. Eur J Cardiothorac Surg. 2013;44(5):843-848. doi: 10.1093/ejcts/ezt146

5. Gerosa G, Scuri S, Iop L, Torregrossa G. Present and future perspectives on total artificial hearts. Ann Cardiothorac Surg. 2014;3(6):595-602. doi: 10.3978/j.issn.2225-319X.2014.09.05 
6. FDA Approves the SynCardia Total Artificial Heart for Destination Therapy Study. SynCardia Systems, Inc (Accessed March 10, 2017)

7. Summay of Safety and Probable Benefit - H040006 AbioCor Implantable Replacement Heart. (Accessed March 05, 2017)

8. Spiliopoulos S, Koerfer R, Tenderich G. A first step beyond traditional boundaries: destination therapy with the SynCardia total artificial heart. Interact Cardiovasc Thorac Surg. 2014;18(6):855-856. doi: 10.1093/icvts/ivu065

9. Gerosa G, Gallo M, Bottio T, Tarzia V. Successful heart transplant after 1374 days living with a total artificial heart. Eur J Cardiothorac Surg. 2016;49(4):e88-89. doi: 10.1093/ejcts/ezv469

10. Torregrossa G, Morshuis M, Varghese R, Hosseinian L, Vida V, Tarzia V, et al. Results with SynCardia total artificial heart beyond 1 year. ASAIO J. 2014;60(6):626-34. doi: 10.1097/MAT.0000000000000132

11. Loforte A, Della Monica PL, Musumeci F. Two years and 4 months: A long-term bridge to transplantation with a total artificial heart. J Heart Lung Transplant. 2011;30(12):1419. doi: 10.1016/j. healun.2011.07.021

12. Kirsch M, Mazzucotelli JP, Roussel JC, Bouchot O, N’Loga J, Leprince P, et al. Survival after biventricular mechanical circulatory support: does the type of device matter? J Heart Lung Transplant. 2012;31(5):501508. doi: 10.1016/j.healun.2011.11.02
13. Copeland JG, Arabia FA, Smith RG, Covington D. Synthetic membrane neo-pericardium facilitates total artificial heart explantation. J Heart Lung Transplant. 2001;20(6):654-656.

14. Kirsch ME, Nguyen A, Mastroianni C, Pozzi M, Léger P, Nicolescu M, et al. SynCardia temporary total artificial heart as bridge to transplantation: current results at la pitié hospital. Ann Thorac Surg. 2013;95(5):16401646. doi: 10.1016/j.athoracsur.2013.02.036

15. Carpentier A, Latrémouille C, Cholley B, Smadja DM, Roussel JC, Boissier E, et al. First clinical use of a bioprosthetic total artificial heart: report of two cases. Lancet. 2015;386(10003):1556-1563. doi: 10.1016/ S0140-6736(15)60511-6

16. Park SS, Sanders DB, Smith BP, Ryan J, Plasencia J, Osborn MB, et al. Total artificial heart in the pediatric patient with biventricular heart failure. Perfusion. 2014;29(1):82-88. doi: 10.1177/0267659113496580

17. Laumen M, Finocchiaro T, Cuenca E, Guersoy D, Spiliopoulos S, Tenderich G, et al. A novel total artificial heart for destination therapy: in-vitro and in-vivo study. Biomed Tech (Berl). 2013.pii: /j/bmte.2013.58. issue-s1-0/bmt-2013-4373/bmt-2013-4373.xml. doi: 10.1515/bmt2013-4373 